\title{
Reinforced concrete corrosion prevention/reduction by hydrophobic impregnation
}

\author{
Michel Donadio ${ }^{1}$, Mirdash Bakalli², Zeno Dan $^{3}$ \\ ${ }^{1}$ Sika Services AG, Switzerland \\ ${ }^{2}$ Sika Technology AG, Switzerland \\ ${ }^{3}$ Sika Europe Management AG, Switzerland
}

\begin{abstract}
The prevention of corrosion in reinforced concrete structures can be achieved by different means. The aim of this paper is to present the efficiency of corrosion prevention using silane hydrophobic impregnation, through laboratory investigations as well from long term field studies. The laboratory investigation was carried out in Zürich, is based on modified ASTM C109, where the product was applied on cracked concrete beams (before cracking and before corrosion initiation; after cracking and before corrosion initiation and finally after cracking and after corrosion initiation). The long term field studies were carried out over 12-years exposure to de-icing salts in a Swiss tunnel, and after 10 years exposure to a marine zone simulation in Japan. This paper will show that the use of a silane hydrophobic impregnation can be an effective way to reduce the risk of corrosion for concrete structures, including structures exposed to chlorides in a marine environment, or from the use of de-icing salts in winter time.
\end{abstract}

\section{Introduction}

The recent disastrous collapse of the Genova Bridge in Italy and different investigations in various countries have shown that the state of bridges in many countries is critical i.e. in need of urgent renovation works.

The cost of corrosion [1] is now well documented by various different organizations including NACE in the USA and the World Corrosion Organization. It is estimated that a quarter of the world's annual steel production is destroyed by corrosion every year. This is equivalent to 150 million tons per year (equivalent to 5 tons/second). The W.C.O. estimates the cost of corrosion as being between 3.1 to $3.5 \%$ of a nation's GDP annually for industrialized countries (e.g. between $€ 1.3$ and 1.4 trillion in USA). As these figures reveal this corrosion is very costly for society and not only financially.

Table 1 shows very clearly that this cost of corrosion versus GDP is also unfortunately not reducing over time.

Table 1: Cost of corrosion (1) in \% of GDP

\begin{tabular}{|l|l|l|}
\hline Country & Year & \% of GDP \\
\hline US & 1950 & 2.1 \\
\hline UK & 1970 & 3.5 \\
\hline Japan & 1974 & 1.2 \\
\hline US & 1975 & 4.5 \\
\hline US & 1988 & 3.1 \\
\hline US & 2013 & 3.1 \\
\hline
\end{tabular}

A study from COMACAC (Morocco) estimated the cost of corrosion at 5\% of GDP, and in France this is estimated to cost from 1 to $2 €$ per day per inhabitant.

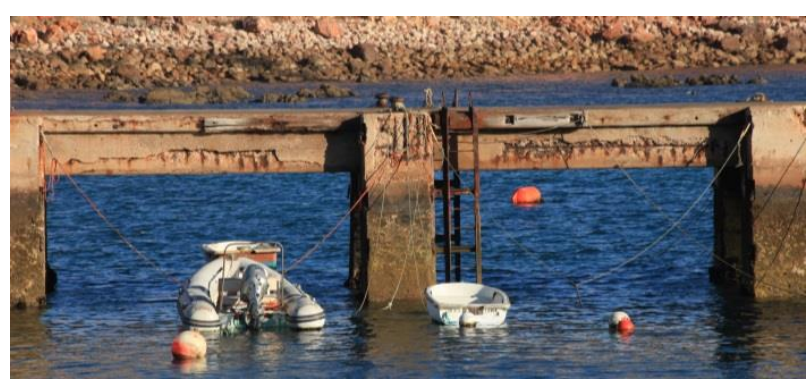

Fig. 1: Example of corrosion of reinforced concrete.

The steel reinforcement in concrete starts to corrode in the presence of moisture when the passive layer formed by the surrounding highly alkaline concrete matrix has broken down due to carbonation, or the presence of chlorides.

To initiate an electrochemical process, several elements are required to be present:

- A loss of passivity (due to carbonation or the presence of chlorides)

- moisture and oxygen

- stray current

To avoid such expense and the risk of eventual collapse of the structures due to steel corrosion, various methods to improve the durability of reinforced concrete structures are available. One of them is to prevent or to reduce the penetration of chlorides, and to dry out the concrete so that the speed of any corrosion that is initiated will be reduced. 
Deeply penetrating, surface applied, hydrophobic, silane based, impregnation materials, such as the liquid type triethoxy $(2,4,4$-trimethylpentyl)silane $\quad(\sim 99 \%$ active content), or the cream type (same chemical base but with $\sim 80 \%$ active content), will reduce the moisture level [2] in the concrete. This reduction of humidity around the reinforcement bars will reduce any corrosion activity (basis of the Principle 8 Resistivity Increase of EN 15049 [3]). Additionally, by preventing moisture ingress, these products will also prevent the further ingress of water-borne chloride ions into the structure

\section{Methodology}

In order to assess the suitability of such deeply penetrating, silane based, hydrophobic impregnations to prevent/arrest corrosion in chloride environments, this paper will summarise the results from three studies, one from laboratory investigations in Switzerland, and two from field testing, in Switzerland and Japan respectively.

\subsection{Swiss Laboratory Investigations [4]}

The cracked concrete beam corrosion test (CCBCT) is a laboratory time-to-corrosion test. It was developed by Paul Tourney and Neal Berke [4] and the test is adapted from ASTM G109 [5].

\subsubsection{Preparation of steel reinforcing bars}

To prevent crevice corrosion during the test, the reinforcing steel bars are prepared as followed:

Table 2: Reinforcing steel bar preparation

\begin{tabular}{|l|l|}
\hline item & Description \\
\hline Type: & $\begin{array}{l}\text { Grey mild steel reinforcing rods, grade } \\
\text { S235JR+AR (EN 10025-2:2004-10) }\end{array}$ \\
\hline Dimension: & Diameter 12 mm, length 914 mm \\
\hline Preparation: & $\begin{array}{l}\text { - Removal of rust particles } \\
\text { mechanically with a power wire brush } \\
\text { - Degreasing the bars with acetone } \\
\text { - Both ends (203 mm - 8 in) of the rods } \\
\text { are fully covered with an epoxy coating } \\
\text { - Both ends are further protected } \\
\text { against crevice corrosion with a heat } \\
\text { shrink tube }\end{array}$ \\
\hline
\end{tabular}

\subsubsection{Concrete Specimens Mix Design}

Production of the concrete mix design was performed according to EN 1766

Cement CEM I $42.5 \mathrm{~N}$

Aggregates:

$355 \mathrm{~kg} / \mathrm{m}^{3}$

W/C:

$0-16 \mathrm{~mm}$

Flow table spread:

Air content:

$33-36 \mathrm{~cm}$

Curing after demoulding:

1.6 to $2.4 \%$

$20^{\circ} \mathrm{C} 95 \% \mathrm{RH}$

\subsubsection{Concrete Specimens}

The test specimens produced are concrete beams with dimensions $150 \times 150 \times 750 \mathrm{~mm}(6 \times 6 \times 30$ in $)$, each with three of the $12 \mathrm{~mm}$ diameter mild steel rebars embedded. Two rebars are placed $38 \mathrm{~mm}$ (1.5 in) from the bottom of the beams, the third $43 \mathrm{~mm}$ (1.7 in) below the top surface of the beams.

No mould release agent was used during production of these beams, in order to prevent any interference with the subsequent application and penetration of the hydrophobic impregnation.

After curing the specimens in a humidity chamber for 28 days, followed by storage for a month at approximately $23^{\circ} \mathrm{C}$, a $5 \mathrm{~mm}(0.2 \mathrm{in})$ deep and $3 \mathrm{~mm}$ (0.1 in) wide notch was sawn into the top surface of the beams. The resulting concrete cover, measured below this cut notch, was $38 \mathrm{~mm}$ (1.5 in).

The sides and the bottom of the beams were painted with two coats of a $100 \%$ epoxy resin coating in order to prevent / limit water evaporation, as well as to prevent contamination from spills of the chloride solution during cyclic ponding.

The bottom rebars were permanently connected to each other with $1.0 \mathrm{~mm}$ diameter copper wire, and the top rebars were electrically short-circuited using a 10ohm resistor soldered onto the copper wire.

A Plexiglas dyke, $305 \mathrm{~mm}$ long, $114 \mathrm{~mm}$ wide and $51 \mathrm{~mm}$ deep, was attached to the top surface of the cracked beams and sealed with an elastic polyurethane sealant. The dyke was used to expose the beams to a $3.0 \%(5.0 \%)$ by mass solution of sodium chloride using a 2-week wet, 2-week dry ponding cycle procedure. During the wet cycle, the dyke was filled to within 20 $\mathrm{mm}$ off the top with sodium chloride solution. The dyke was also covered with a plastic plate in order to avoid/limit water evaporation.

The average time period between the end of the 28 day curing period and the subsequent cracking procedure was: 2 months (average time period between casting and cracking the beams: 3 months).

The average time period between the end of the 28day curing period and the start of the first ponding cycle was: 3 months (average time period between casting the beams and the beginning of the first ponding cycle: 4 months). After concrete curing, all of the specimens were stored in the laboratory at approximately $23^{\circ} \mathrm{C}$.

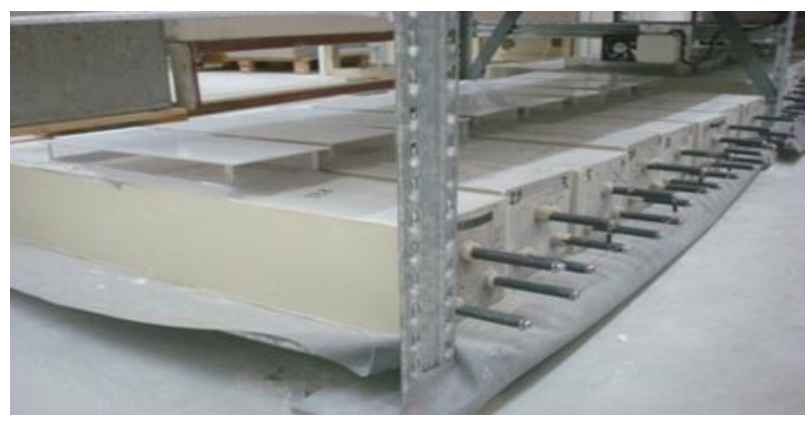

Fig. 1: Prepared concrete beams for corrosion testing.

\subsubsection{Testing Concept}

The products to be tested were applied at different intervals and to mimic different field scenarios:

- Before cracking (forced) and Before corrosion initiation $(\mathbf{B} / \mathbf{B})$ 
- After cracking (forced) and Before corrosion initiation (A/B)

- After cracking (forced) and After corrosion initiation (A/A)

\subsubsection{Forced Cracking Procedure}

Each beam was carefully cracked along the cut notch using flexural load bearing techniques, so that the crack extended down to the top rebar. Whilst under the cracking load, the crack was shimmed to a consistent crack size to be used throughout the whole corrosion test. For this purpose three to four $0.25 \mathrm{~mm}(0.01 \mathrm{in})$ thick stainless steel shims were inserted into the crack at intervals to hold it open once the load was released.

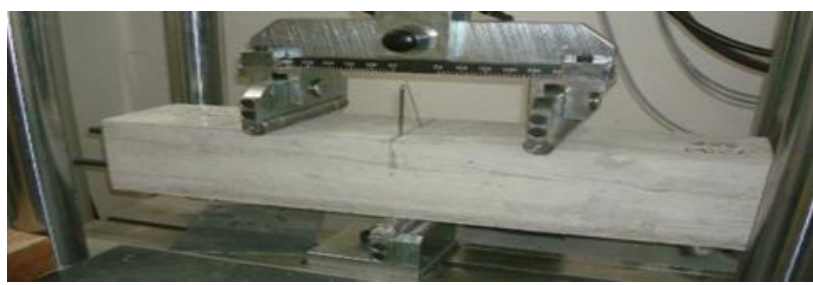

Fig. 2: Forced cracking.

\subsubsection{Selection of the Hydrophobic Products}

Two liquid hydrophobic products were selected for the test; the first was triethoxy(2,4,4-trimethylpentyl)silane based with $\sim 99 \%$ active content (Product A) and the second product was an organo-functional silane with 98\% active content and claiming to also contain a corrosion inhibitor (Product X).

\subsubsection{Application Procedure for Hydrophobic Products}

Two consumption rates were used for Product A corresponding to $300 \mathrm{~g} / \mathrm{m}^{2}$ which was applied in 2 coats and to $500 \mathrm{~g} / \mathrm{m}^{2}$ which was applied in 3 coats.

One consumption rate of $500 \mathrm{~g} / \mathrm{m}^{2}$ (corresponding to the typical recommended rate and applied in 3 coats, was used for Product X.

\subsubsection{Ponding Procedure}

Initially, the ponding exposure was performed for 19 cycles with a $3.0 \%$ by mass of sodium chloride solution, on the basis of a 2-week wet, 2-week dry ponding cycle.

Beginning with the $20^{\text {th }}$ cycle, the sodium chloride concentration of the ponding solution was increased to $5.0 \%$ by mass, in order to further accelerate the CCBCT, thereby achieving even harsher test conditions.

\subsubsection{Electrochemical Measurements}

Different methods [7][8] of testing were used to assess the corrosion activities of the different concrete specimens:

- Corrosion Potential

- Corrosion Current

- Integral Corrosion Current

\subsection{Japanese Field Study [9]}

Miho Tsujita of Kagoshima University of Japan conducted a study over a 10 year period on beams placed in the simulated exposure of a shower of salted water, designed to simulate 10 years exposure in a splash zone.

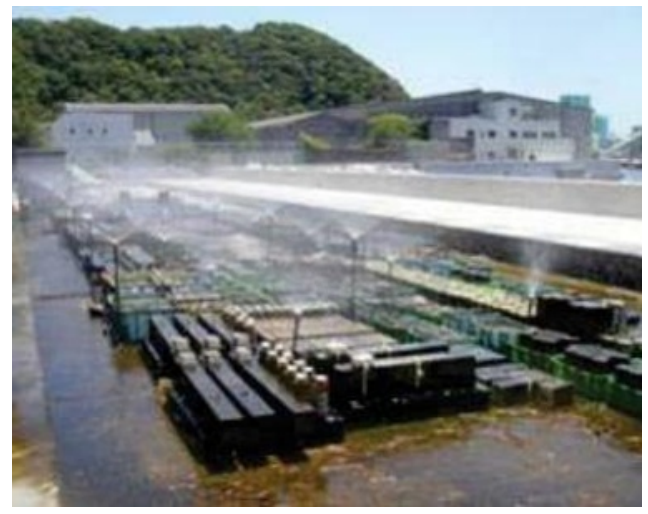

Fig. 3: Test site for salt spray exposure testing at the Kagoshima University in Japan.

\subsubsection{Concrete mix design for Japanese specimens}

Cement: $\quad$ OPC $243 \mathrm{~kg} / \mathrm{m}^{3}$

Sand: $\quad$ River sand $912 \mathrm{~kg} / \mathrm{m}^{3}$

Aggregates: Sandstone $20 \mathrm{~mm} 970 \mathrm{~kg} / \mathrm{m}-$

W/C: $\quad 0.68$

Air: $\quad 4.0 \%$

Size: $\quad 100 \times 100 \times 150 \mathrm{~mm}$

Rebar: $\quad$ Two deformed steel bars $(\varnothing 10 \mathrm{~mm})$

Cover: $\quad 45 \mathrm{~mm}$ and $17.5 \mathrm{~mm}$ from the two opposite exposed sides of the specimens.

Cure: $\quad 28$ days in water

Types: $\quad 1$ set of specimens without cracks (NC) 1 set with cracks induced BEFORE surface treatment (BC) 1 set with cracks induced AFTER surface treatment $(\mathrm{AC})$

Note: with the exception of the two exposed surfaces, all of the other four beam surfaces were coated with epoxy resin to prevent additional side penetration of chlorides.

\subsubsection{Selection of Hydrophobic \& Surface Improvement Products}

Table 3: Types of surface treatment materials

\begin{tabular}{|l|l|l|l|l|}
\hline & Type & Aspect & Component & $\%$ \\
\hline A & Silane & Liquid & $\begin{array}{l}\text { Silane } \\
\text { Alcohol }\end{array}$ & $\begin{array}{l}\sim 34 \\
\sim 66\end{array}$ \\
\hline B & Silane/Siloxane & Cream & $\begin{array}{l}\text { Alkylalkoxysilane } \\
\text { Ethanol }\end{array}$ & NA \\
\hline C & Silane/Siloxane & Gel & $\begin{array}{l}\text { Trietoxysilane } \\
\text { Ethanol }\end{array}$ & $\begin{array}{l}\sim 90 \\
\sim 5\end{array}$ \\
\hline D & Siloxane & Liquid & $\begin{array}{l}\text { Silane/siloxane } \\
\text { Distilled liquid }\end{array}$ & $\begin{array}{l}60- \\
100\end{array}$ \\
\hline E & Silicate & Liquid & $\begin{array}{l}\text { Super silicate } \\
\text { particle }\end{array}$ & $30-60$ \\
& & & Catalyst & \\
\hline F & Acrylic Silicate & Liquid & Emulsion & NA \\
\hline
\end{tabular}

All of the specimens were allowed to dry for 2 weeks after application at a constant temperature of $20^{\circ} \mathrm{C}$. 


\subsubsection{Exposure tests}

All of the specimens with the surface impregnated materials were exposed to simulated splash zone conditions using the salt water shower. This test facility is located in the Kurihama bay area (Yokosuka, Kanagawa prefecture, Japan) and has artificially repeated dry and wet cycles, that is, salt water shower for about four hours and then natural drying in the air for eight hours in each cycle (Fig. 3). One day consisted of two cycles and the total exposure time was 10 years.

\subsubsection{Measurements}

After 10 years exposure to repeated cycles of wetting with salt water and subsequent drying, the following assessments and measurements were carried out:

- Penetration depth of the tested products

- Carbonation depth

- Corrosion of the steel bars

\subsection{Swiss Field Study [10]}

Yves Schiegg has reported the results of a 12-year long field study aimed at investigating the corrosion behaviour of ordinary and stainless steel rebars in various types of concretes.

\subsubsection{Composition of the Concrete Plate Specimens}

Table 4: Composition of concrete plate specimens

\begin{tabular}{|c|c|c|c|}
\hline Ref. & Type & $\mathrm{W} / \mathrm{C}$ & Rebar \\
\hline H1-H4 & CEM I (reference) & 0.50 & \multirow{6}{*}{$\begin{array}{l}\text { Carbon Steel } \\
\text { B500B }\end{array}$} \\
\hline G1-G4 & CEM I & 0.35 & \\
\hline D1-D4 & CEM I + 20\% Slag & 0.50 & \\
\hline E1-E4 & CEM I + 15\% Fly ash & 0.50 & \\
\hline F1-F4 & $\begin{array}{l}\text { CEM I + 7\% silica } \\
\text { fume }\end{array}$ & 0.50 & \\
\hline $\mathrm{A} 1-\mathrm{A} 4$ & $\begin{array}{l}\text { Reference + } \\
\text { hydrophobic }\end{array}$ & 0.50 & \\
\hline B1-B4 & Reference & 0.50 & $\begin{array}{l}\text { Galvanised } \\
\text { carbon steel }\end{array}$ \\
\hline $\mathrm{C} 1-\mathrm{C} 4$ & Reference & 0.50 & Stainless Steel \\
\hline
\end{tabular}

\subsubsection{Field Exposure Panel in the Naxberg Tunnel}

The Naxberg tunnel is located on the Swiss A2 motorway, close to the Gotthard tunnel and at around $1000 \mathrm{~m}$ altitude. As a part of scheduled tunnel restoration work at the end of the 1990's, the opportunity was provided to place a concrete test panel in the tunnel wall at a distance of $50 \mathrm{~m}$ from the north-facing tunnel entrance (Fig. 4). The panel consisted of 32 concrete plate specimens, each with the dimensions of $600 \times 500$ $\mathrm{x} 100 \mathrm{~mm}$

Due to the different positions of the plates (height / distance from road (0 to $2.4 \mathrm{~m}$ ), the exposure class according to European standard EN 206 was expected to vary from XD3 (alternating wet/dry with exposure to chloride-containing spray water) to XD1 (moderately wet with exposure to chloride-containing mist water).

\subsubsection{Test Measurements}
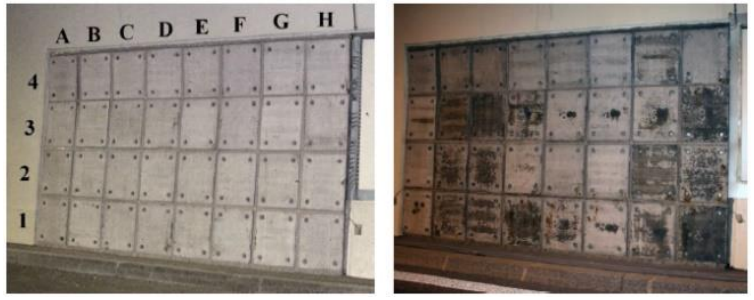

Fig. 4: Visual state of the concrete test panels in the Naxberg tunnel in the year 2000 (left) and 2012 (right).

Various test measurements were carried out on the concrete plates from the panels during this investigation. This paper will only present some extracts of these results on

- Carbonation depth,

- Chloride profiles

- Corrosion profiles.

\section{Test Results}

\subsection{Swiss Laboratory Investigations}

Only the macrocell measurements are presented in this paper.

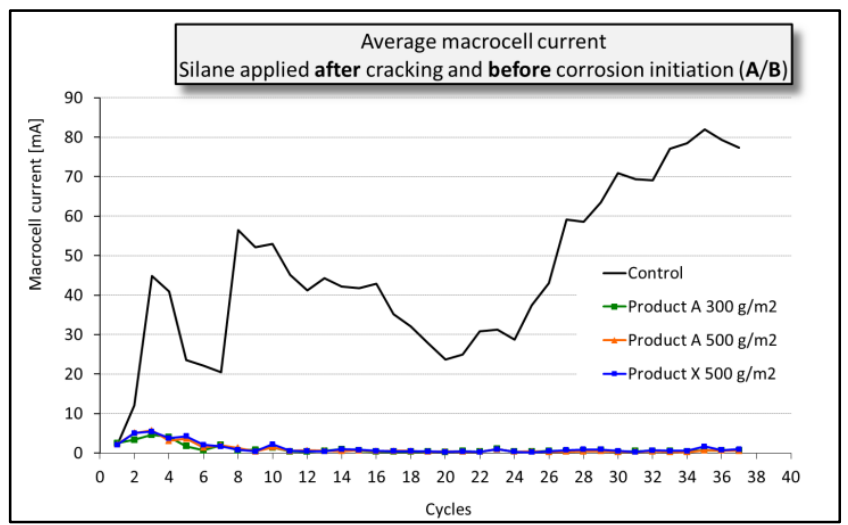

Fig. 5: Macrocell measurements - Silane applied after cracking $\&$ before corrosion initiation

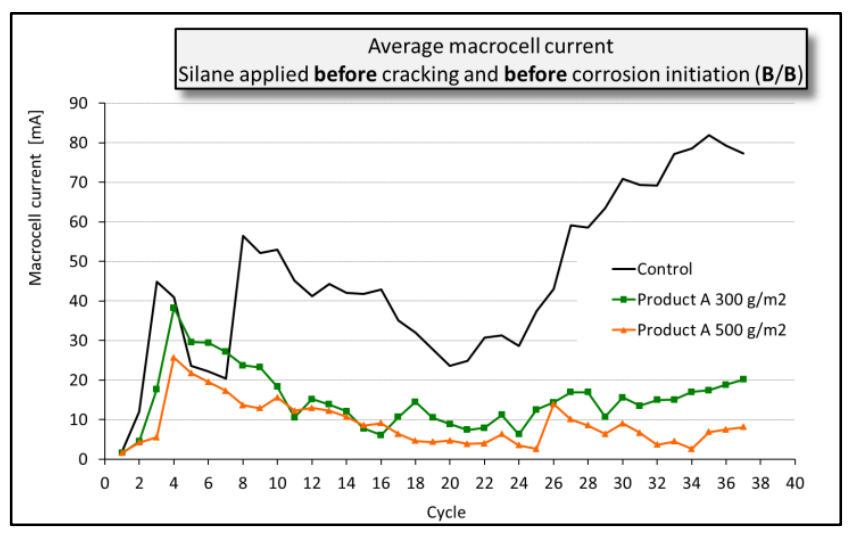

Fig. 6: Macrocell measurements - Silane applied before cracking \& before corrosion initiation 


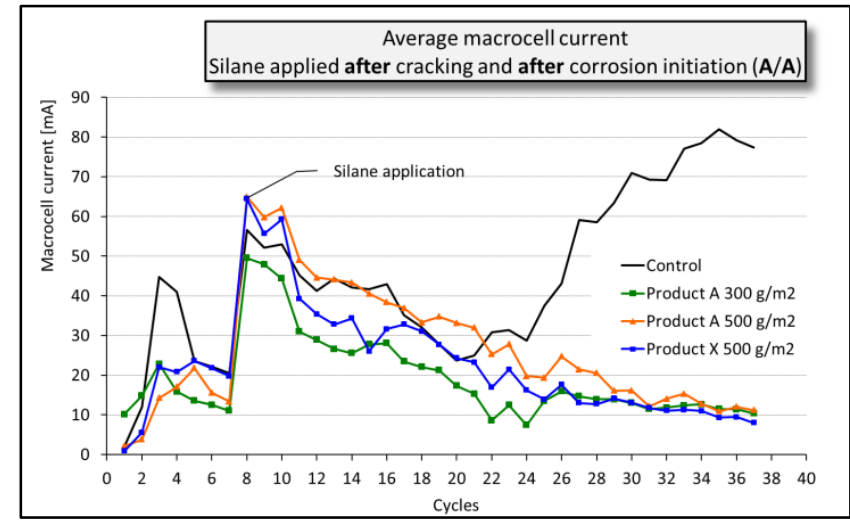

Fig. 7: Macrocell measurements - Silane applied after cracking $\&$ after corrosion initiation

\subsection{Japanese Field Study}

Note: The numbers in bracket in the following graphs correspond to the concrete cover.

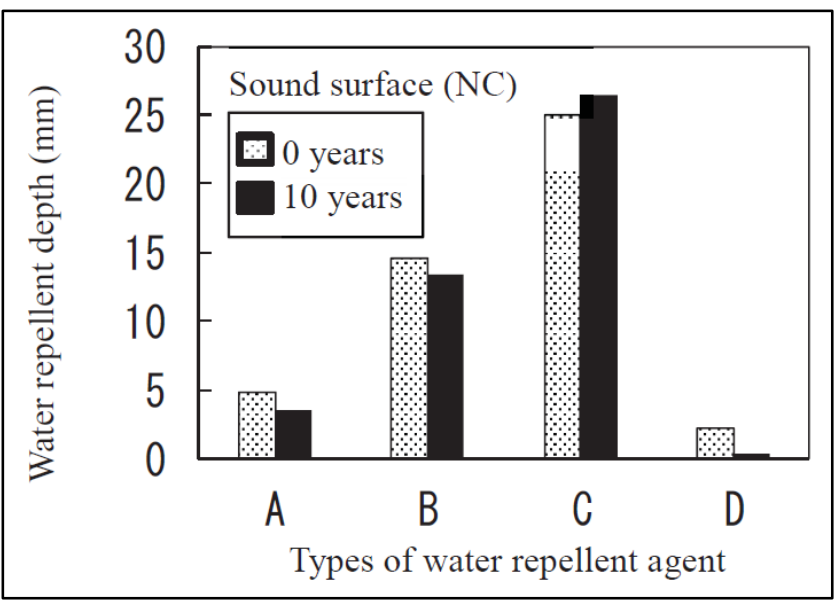

Fig. 8: Penetration depth of hydrophobic specimens at the start and at the end of the study

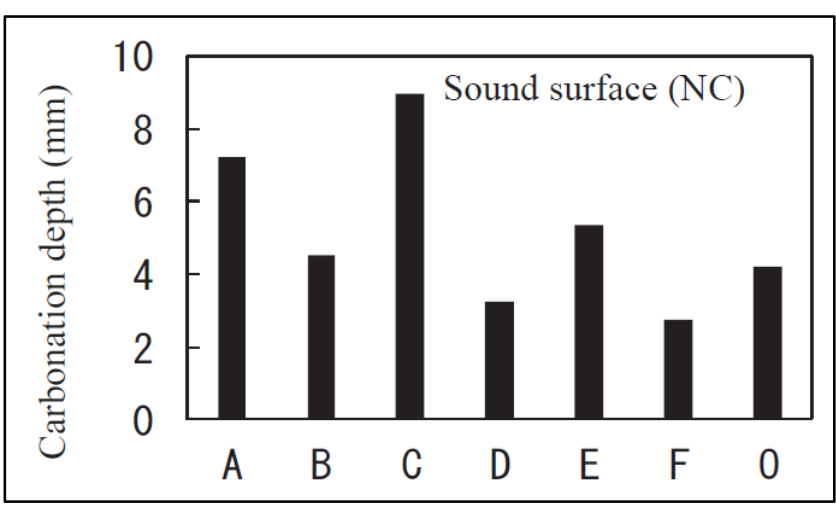

Fig. 9: Carbonation depth of treated specimens versus control (0) on non cracked concrete surfaces.

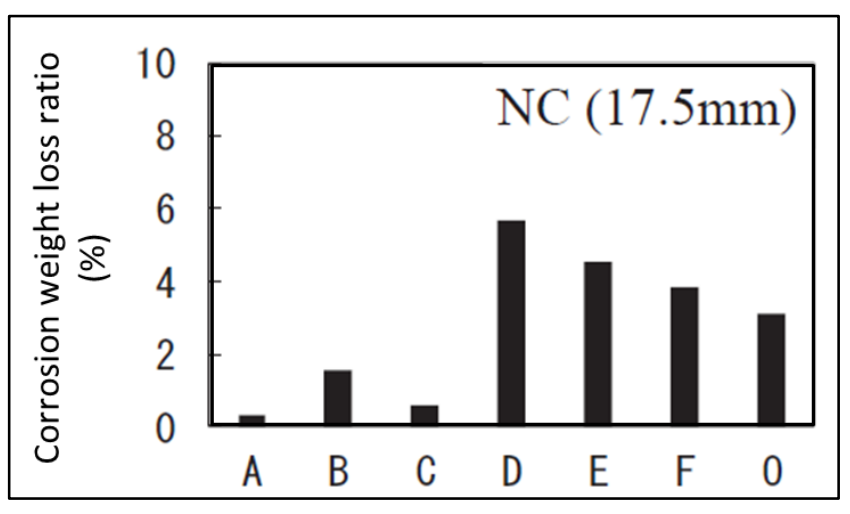

Fig. 10: Corrosion levels with low concrete cover on noncracked surfaces.

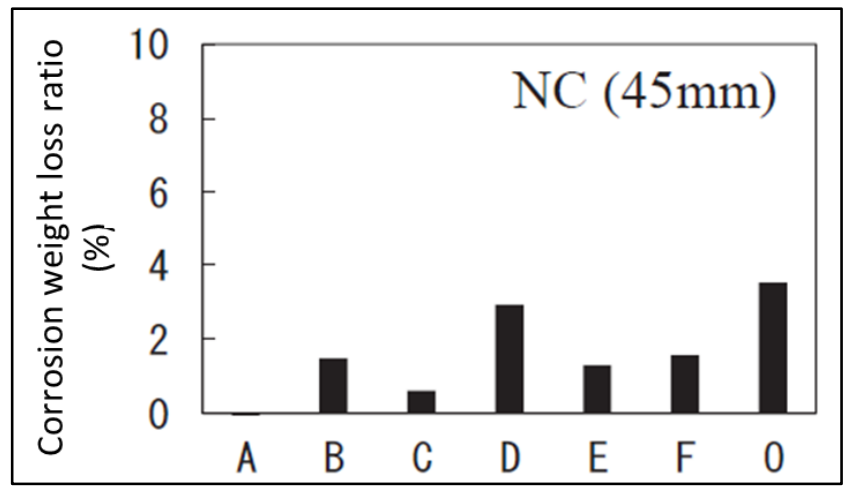

Fig. 11: Corrosion levels of normal concrete cover on noncracked surfaces.

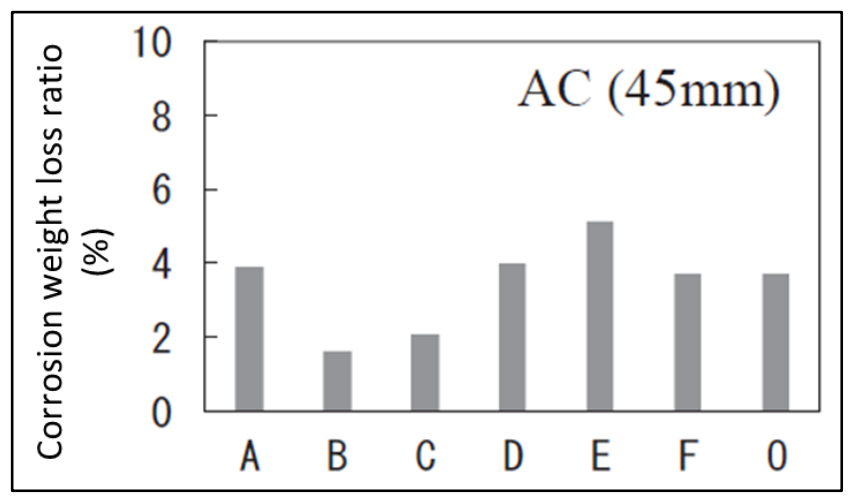

Fig. 12: Corrosion levels of normal concrete cover on cracked surfaces - surface treatment carried out AFTER cracking

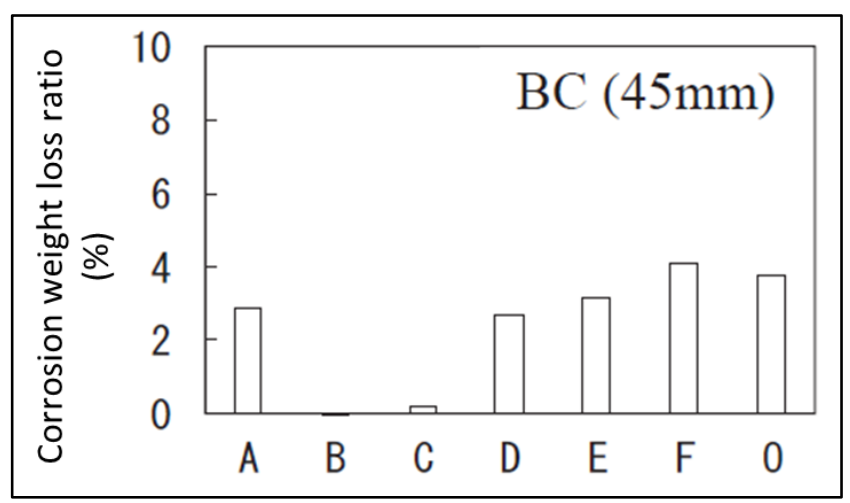

Fig. 13: Corrosion levels of normal concrete cover on cracked surfaces - surface treatment carried out BEFORE cracking 


\subsection{Swiss Field Study}

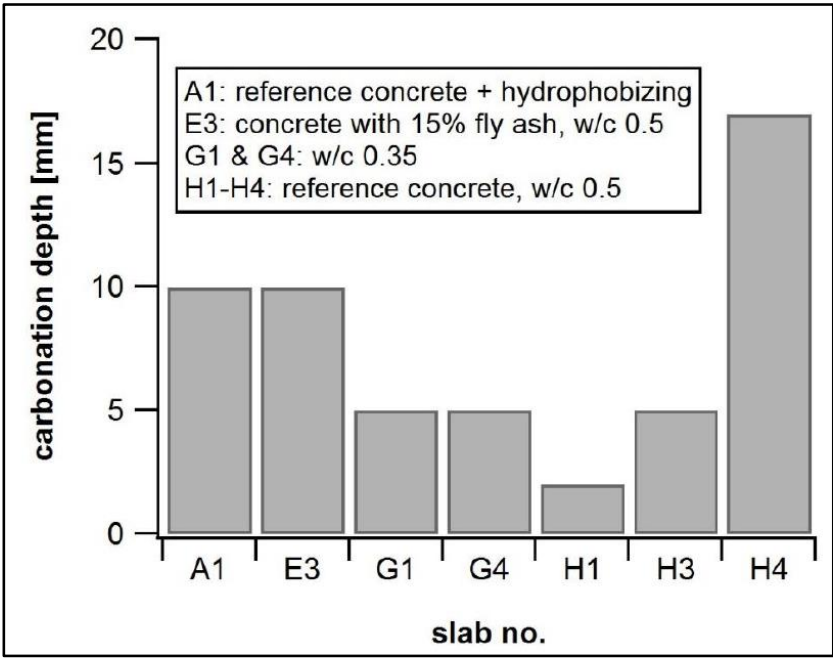

Fig. 14: Carbonation depth after 12 years exposure in the Naxberg tunnel.

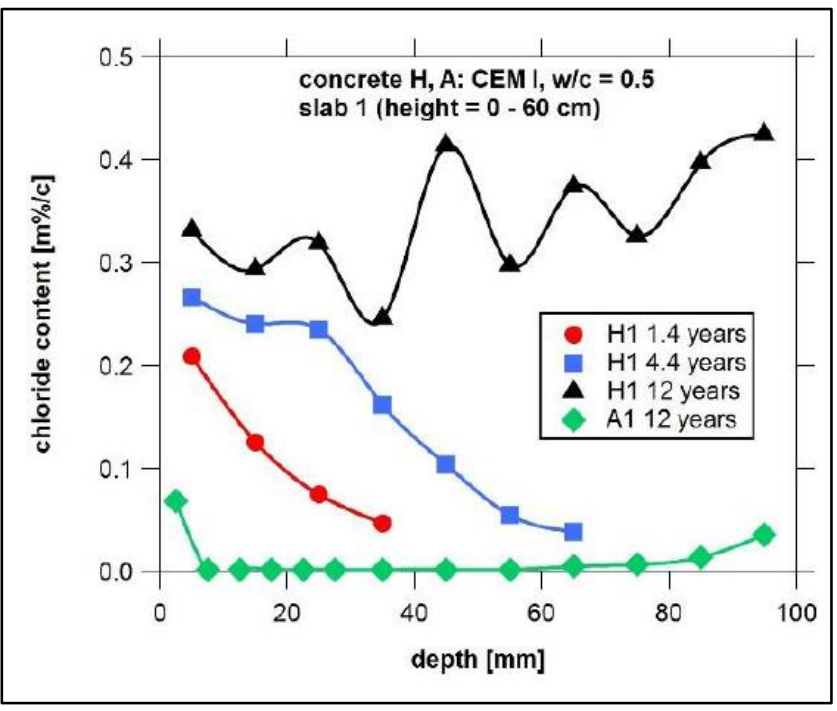

Fig. 15: Chloride profiles on the lower plate of the control specimens compared to the specimen treated with the hydrophobic impregnation.

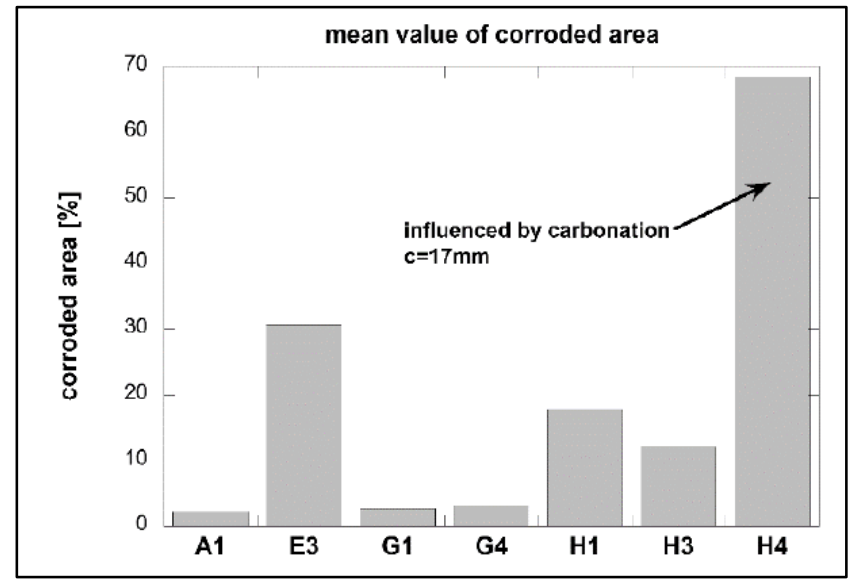

Fig. 16: Average corroded surface area of the steel rebars

\section{Discussion}

\subsection{Swiss Laboratory Investigations}

Figure 5 clearly shows that the hydrophobic impregnation provides the best increase in protection when applied after the cracks have already formed.

When the cracks happen after application of the treatment (refer to figure 6), we can also see the importance of the materials consumption (closely related to their penetration depth) in the level of protection.

Also when the treatment is carried out once corrosion is already advanced, we can also see a positive effect from the relative drying-out of the specimens on reducing corrosion activities - this is further confirmed by independent tests carried out by ZAG (Slovenian National Building \& Civil Engineering Institute) [11].

The lack of difference between the two different products tested shows that the positive effect of prevention / reduction of corrosion is achieved due to the hydrophobic performance of the two products.

\subsection{Japanese Field Study}

Unfortunately no information was provided in the original paper about the consumption rates of the different products used.

However, from the type of product selected and the penetration levels achieved (refer to fig 8), it clearly shows that to obtain efficient protection against corrosion, even in the presence of cracks, high performance, deeply penetrating products such as the cream (B) and gel (C) will provide significant protection. This 10 years study also shows the limited efficiency of silicate based products $(\mathrm{E} \& \mathrm{~F})$ in arresting the corrosion.

\subsection{Swiss Field Study}

Unfortunately no information is provided in the original paper about the type and consumption rate of the hydrophobic impregnation used.

However, during the subsequent discussion at the EUROCORR2017 conference where the paper was presented, it was stated by the author that the product used was similar to the triethoxy(2,4,4-trimethylpentyl) silane (Product A) used in the above Swiss Laboratory Investigations.

The carbonation depth (Fig. 14) of these different specimens confirmed the results from the Japanese study, showing that hydrophobic impregnation products are not intended for arresting carbonation.

However, Figure 15 above clearly shows the benefit of using these types of products for arresting the penetration of chlorides as at the typical depth $(50 \mathrm{~mm})$ of steel reinforcement. The control specimens show that after 12 years of exposure chloride levels up to almost $0.4 \%$ by weight of cement, whilst the specimens treated with hydrophobic products show no chlorides penetrating the concrete at this depth.

Figure 16 shows a low level of corrosion in the treated standard concrete specimen at the same level as the concrete with a very low water / cement ratio $(\mathrm{G})$. 
The author of this study concludes that it is clearly of benefit to protect such exposed reinforced concrete structures with this type of hydrophobic impregnations: "After 12 years of exposure only the plates that contained stainless steel rebar or were hydrophobically treated showed no rust spots on the surface".

\section{Conclusions}

To reduce the costs related to steel corrosion in reinforced concrete infrastructure, these laboratory investigations and field studies have all demonstrated that treatment of concrete with deeply penetrating, hydrophobic impregnations such as the liquid product triethoxy(2,4,4-trimethylpentyl) silane, or the cream/gel equivalent version of the product, will effectively reduce chloride migration, and therefore arrest or mitigate established corrosion. Other benefits from the application of such products are the prolongation of the time to repair and increased service-life of the concrete structures. In addition the professional and periodic application of deeply penetrating, hydrophobic impregnations will also significantly contribute to increasing the durability and safety with lower risk structures.

\section{References}

1. Sources: World Corrosion Organization, NACE, COMACAC, IMIST-CNRSTC (2011 - 2015)

2. E. R. Giannini, University of Texas. Coatings and overlays for concrete affected by alkali-silica reaction. Eds. M. Grantham, V. Mechtcherine, U. Schneck, CRC Press, pp. 823-831, (2011)

3. EN 1504-9-2008; Products and systems for the protection and repair of concrete structures Definitions, requirements, quality control and evaluation of conformity - Part 9: General principles for the use of products and systems. (2008)

4. M. Donadio, Internal Sika Article, corrosion tests on cracked concrete beams. Adapted from ASTM G109 (2018)

5. Paul Tourney and Neal Berke, Concrete International. A Call for Standardized Tests for Corrosion-Inhibiting Admixtures, (1993), p. 57-62

6. ASTM G109-07-2013, Standard Test Method for Determining Effects of Chemical Admixtures on Corrosion of Embedded Steel Reinforcement in Concrete Exposed to Chloride Environments, ASTM International, West Conshohocken, PA, (2013)

7. ASTM C876-15, Standard Test Method for Corrosion Potentials of Uncoated Reinforcing Steel in Concrete, ASTM International, West Conshohocken, PA, (2015)

8. Corrosion of Reinforcement in Concrete Monitoring, Prevention and Rehabilitation Techniques, Eds. by M. Raupach, B. Elsener, R. Polder and J. Mietz, EFC Publication No. 38, Woodhead Publishing, (2007)
9. Mijo Tsujita et all, School of Science and Engineering, Kagoshima University, Japan. Proceedings of Hydrophobe VIII, Hong Kong, Effect of surface treatment materials on corrosion protection of concrete structures subjected to chloride attack: An experimental study. (2017)

10. Yves Schiegg et all, Technology and Research for Concrete Structures. EUROCORR2017. Monitoring rebar corrosion propagation in concrete - Results of the Naxberg field experiment after 12 years. (2017)

11. Report from the Slovenian National Building and Civil Engineering Institute; P859/11-440-1. Corrosion testing and visual assessment of reinforced concrete beams treated with Sikagard ${ }^{\circledR}$ 705 L. (2011) 